\title{
Stent-Assisted Coil Embolization of Posterior Communicating Artery Aneurysms
}

\author{
Y.D. Cho, W.J. Lee, K.M. Kim, H.-S. Kang, J.E. Kim, and M.H. Han
}

\begin{abstract}
BACKGROUND AND PURPOSE: Use of protective stents may not be effective in coil embolization of wide-neck aneurysms involving the posterior communicating artery. Successful implementation depends on the caliber of the vessel, its angle of origin, and the manner in which its orifice is incorporated into the aneurysm. Presented here are the results (clinical and radiographic) of coil embolization in aneurysms of the ICA-posterior communicating artery junction, variably aided by stents. The primary focus is angiographic configurations that impact stent placement.
\end{abstract}

MATERIALS AND METHODS: From a prospective data repository, we retrieved records of 32 consecutive patients with 33 posterior communicating artery aneurysms, all of which were treated by stent-assisted coil embolization between June 2008 and August 2012. Outcomes were analyzed in terms of aneurysm configuration and clinical status.

RESULTS: Stents were positioned entirely in the ICA $(n=26)$, from the ICA to the posterior communicating artery $(n=2)$, in the posterior communicating artery only $(n=3)$, and retrograde from the posterior communicating artery to the ICA terminus $(n=2)$. Procedurerelated complications occurred in 3 patients (9.1\%), but only 1 (3.0\%) had mild neurologic sequelae (Glasgow Outcome Score 4). Using coil embolization, we achieved successful occlusion in 24 aneurysms (72.7\%), and in 9 others, subtotal occlusion was conferred. During a mean follow-up of $15.7 \pm 10.7$ months, imaging of 27 aneurysms documented stable occlusion in $19(70.4 \%)$, whereas angiography of 15 aneurysms (39.5\%) disclosed 2 instances of in-stent stenosis (13.3\%) and a solitary occurrence of stent migration (6.7\%).

CONCLUSIONS: In posterior communicating artery aneurysms, stent protection during coil embolization is feasible by adjusting the procedural strategy to accommodate differing configurations of the aneurysm and its vascular source.

ABBREVIATIONS: GOS = Glasgow Outcome Score; PcomA = posterior communicating artery

CA-PcomA junctional aneurysms constitute about $50 \%$ of ICA aneurysms and $25 \%$ of all intracranial aneurysms. ${ }^{1}$ Due to anatomic variations in parent arteries and the array of configurations displayed by the aneurysms themselves, these lesions may be among the easiest or the most difficult to treat by any means, surgical or endovascular. ${ }^{2}$ Technologic advancements and improved coiling techniques have made it possible to treat a large percentage of oddly configured aneurysms, otherwise incondu-

Received November 20, 2012; accepted after revision January 21, 2013

From the Departments of Radiology (Y.D.C., W.J.L., K.M.K., M.H.H.) and Neurosurgery (H.-S.K., J.E.K., M.H.H.), Seoul National University Hospital, Seoul National University College of Medicine, Seoul, Korea.

This study was supported by a grant of the Korea Health Care Technology R\&D Project, Ministry for Health, Welfare and Family Affairs, Republic of Korea (A111101). Please address correspondence to Moon Hee Han, MD, PhD, Departments of Radiology and Neurosurgery, Seoul National University College of Medicine, 28 Yongon-dong, Jongno-gu, Seoul, Korea, 110-744; e-mail: hanmh@snuh.org

- Indicates open access to non-subscribers at www.ajnr.org

http://dx.doi.org/10.3174/ajnr.A3541 cive to endovascular coil embolization. The utility of augmenting coil embolization through stent usage has also been recognized in recent years and is now established as a useful and effective mode of treatment. ${ }^{3-9}$ However, the protective effect of a stent is sometimes limited in wide-neck PcomA aneurysms. Such aneurysms tend to incorporate the origin of the PcomA, and the affected branch often arises from the ICA or the aneurysm neck at an acute angle. Herein we present the clinical and radiographic outcomes of stent-assisted coil embolization in ICA-PcomA aneurysms, focusing on case-specific dictates of stent placement (vessel anatomy and configuration of the aneurysm) and immediate or delayed stent-related complications.

\section{MATERIALS AND METHODS Population}

Between June 2008 and August 2012, we performed endovascular treatment of 1745 intracranial aneurysms for 1373 patients, including 227 PcomA aneurysms. Of these, 32 consecutive patients with 33 PcomA aneurysms were reviewed via prospectively ac- 
crued data. Stent assistance had been used in each instance. Patients with nonjunctional PcomA aneurysms (so-called "true" PcomA aneurysms) were excluded from the study, as were those with dissecting, fusiform, blood blister-like, or false aneurysms. Informed consent was obtained from each patient on the basis of the perceived risks, benefits, and treatment alternatives (ie, aneurysm clipping) after thorough evaluations. Therapeutic decisionmaking entailed a multidisciplinary deliberation of both surgical and nonsurgical neurointerventions.

\section{DSA and Endovascular Procedures}

The configuration of each aneurysm and the architecture of its arterial supply were delineated by using an Integris V (Philips Healthcare, Best, the Netherlands) biplane system, which included high-resolution $3 \mathrm{D}$ rotational angiography. The size of the aneurysm was defined as its broadest diameter in 3D configuration. Neck size and depth-to-neck ratio were measured on a working projection of the DSA. The following PcomA types were designated on the basis of the PcomA-to-P1 ratio of arterial diameters (PcomA/P1): fetal (no P1), dominant ( $>1.5$ ), iso-type (0.5-1.5), hypoplastic $(<0.5)$, and perforator (when the PcomA is a thalamoperforator, with no connection to P1). In addition, aneurysms were stratified by the degree of neck incorporation as PcomA incorporation, equivocal, or ICA incorporation type. The latter was based on the degree of PcomA involvement in the aneurysm neck (relative to its diameter). The angle of the PcomA was estimated at its origin from the distal ICA.

In all cases, the procedures were performed with the patient under general anesthesia, and all patients with unruptured aneurysms were given antiplatelet medication before the procedure. According to the protocol of our institution, dual antiplatelet agents (clopidogrel and aspirin) were administered when stent protection was anticipated during the procedure. In patients showing poor response to clopidogrel based on the VerifyNow P2Y12 assay (Accumetrics, San Diego, California), ${ }^{10}$ cilostazol was added. A bolus of $3000 \mathrm{IU}$ of heparin was administered after femoral artery sheath placement, and intermittent boluses of $1000 \mathrm{IU}$ per hour were then administered. Activated clotting time was monitored every hour. On completing the endovascular procedure, tirofiban or heparin infusion was maintained for up to 12 hours in cases involving procedural thromboembolism. Maintenance of dual antiplatelet medication was recommended for at least 3 months after the procedure, and a single agent, for at least 1 year.

In patients with ruptured aneurysms, antiplatelet premedication was not performed. In these cases, systemic heparinization was initiated after adequate protection of the aneurysms. After the procedure, a loading dose of clopidogrel and aspirin was administered and maintenance of the medication was the same as that in unruptured aneurysms.

\section{Clinical and Radiologic Follow-Up}

In patients with unruptured aneurysms, MRA with 3D reconstruction or plain radiography or both were recommended 6,12 , 24 , and 36 months after coil embolization. Additional plain radiography was recommended 1 and 3 months postembolization in patients presenting with hemorrhage. Conventional angiography was recommended at the time of 12-month follow-up when as- sessing the status of the treated aneurysms with MRA was not feasible or when aneurysmal recanalization was suspected by noninvasive evaluation, such as MRA or plain radiography, to decide whether further treatment was necessary.

\section{Immediate and Final Outcome}

The degree of aneurysmal occlusion was assessed by completion angiography with a 3-point scale: total occlusion (no residual filling of contrast medium in the aneurysm), near-total occlusion (a small amount of residual contrast filling at the base of the aneurysm), and subtotal occlusion (any contrast filling in the aneurysmal sac).

Clinical outcomes were assessed with the Glasgow Outcome Score, and anatomic follow-up results were categorized as follows: stable occlusion (no interval change since the procedure or progressive thrombosis within the aneurysm), minor recanalization (progressive filling limited at the neck of the aneurysm), and major recanalization (aneurysmal sac filling).

This study was conducted with the approval of the institutional review board of the Seoul National University Hospital.

\section{RESULTS}

\section{Population Distribution}

Study subjects included 4 men and 28 women, with a mean age of $60.0 \pm 10.1$ years. Five aneurysms $(15.2 \%)$ presented with subarachnoid hemorrhage, and a stent was used to treat 12 (36.4\%) recanalized aneurysms. Aneurysm size (excluding recanalized lesions) ranged from 3.0 to $17.2 \mathrm{~mm}$ (mean, $7.1 \pm 4.0 \mathrm{~mm}$ ). All 33 aneurysms were wide-neck, with dome-to-neck ratios $<1.5$.

The distribution of PcomA types was as follows: fetal, 6; dominant, 5; iso, 9; hypoplastic, 8; and perforator, 2. In 3 instances, a determination could not be made by angiography. The angles of PcomA origin ranged from $-19^{\circ}$ to $102^{\circ}$ (mean, $26.9 \pm 30.0^{\circ}$ ). The necks of the aneurysms primarily incorporated the ICA in 21 , whereas 8 were considered equivocal and only 4 distinctly involved the PcomA.

An algorithm of stent positioning in coil embolization of PcomA aneurysms, as generated by this study, is shown in Fig 1. The strategies are differentiated by the degree of PcomA integration into the aneurysm neck, PcomA type, and angle of PcomA origin.

\section{Procedural Results}

Stent Deployment. In our series, stents were deployed as follows: $1)$ the distal ICA to the ICA bifurcation $(n=26) ; 2)$ the distal ICA to the PcomA $(n=2) ; 3)$ the PcomA only, aligning the proximal portion of the stent to the aneurysm neck $(n=3)$; and 4$)$ the PcomA to the ICA bifurcation, retrograde $(n=2)$ (Fig 2). Opencell stents (Neuroform; Stryker Neurointerventional, Fremont, California) were used in 5 aneurysms, with closed-cell stent placement (Enterprise; Codman \& Shurtleff, Raynham, Massachusetts) in the remaining 28 . The stents were used to prevent coil protrusion into the parent artery in 25 aneurysms, to stabilize protruded coils in 6, and to anticipate the flow-diversion effect of the stent in 2 aneurysms in which successful occlusion failed. Stents were deployed before coil insertion in 15 aneurysms, during the coiling procedure in 12 , and after completion of coiling in 6 .

In patients stented entirely in the ICA, coil embolization of the 


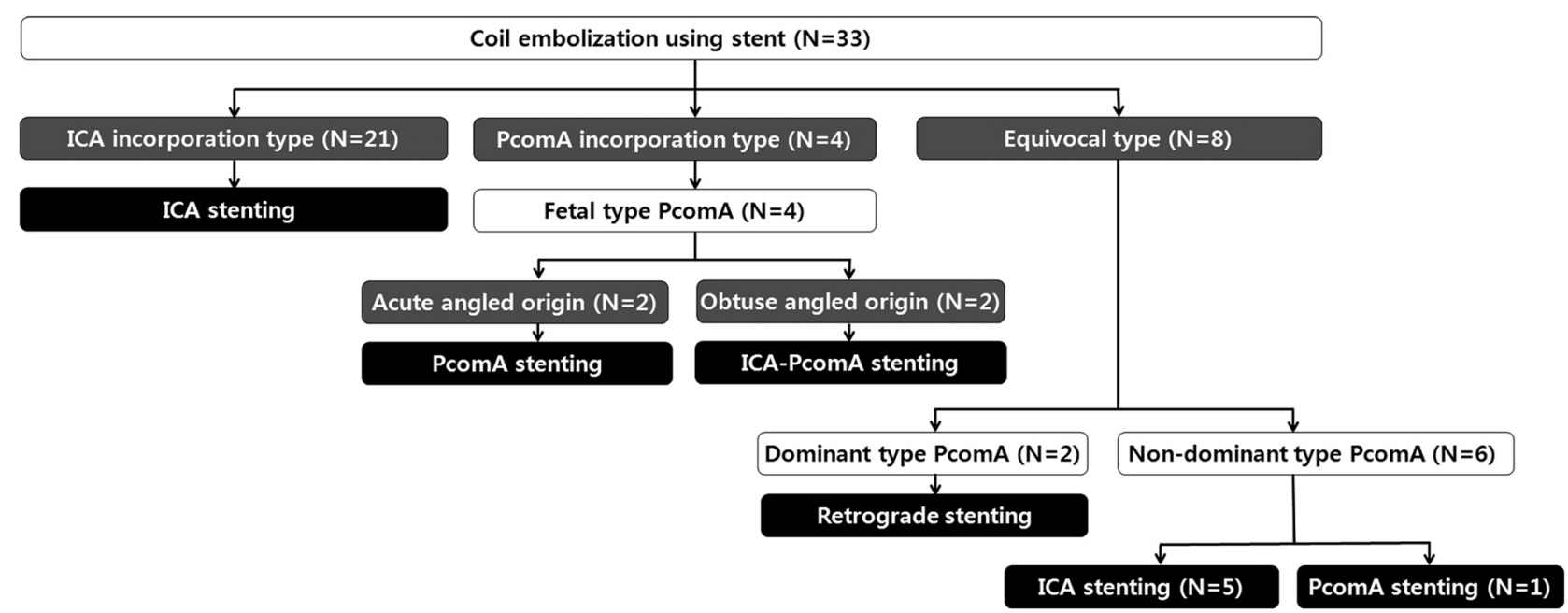

FIG 1. Algorithm for positioning of the stent in coil embolization of PcomA aneurysms, adjusting for PcomA integration into the aneurysm neck, PcomA type, and angle of PcomA origin.
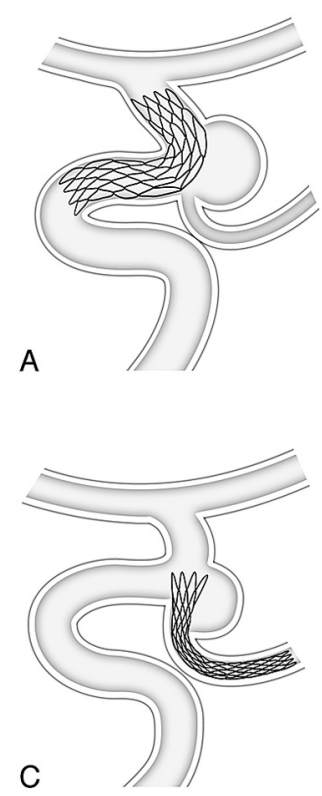

FIG 2. $A$, If the aneurysm neck mostly incorporates the distal ICA or the coil protrudes into the distal ICA, stent positioning from the distal ICA to the terminal ICA preserves ICA patency. $B$, If the aneurysm neck mostly incorporates the PcomA or the coil protrudes into the PcomA, stent positioning from the distal ICA to the PcomA preserves PcomA patency. $C$, If the PcomA warrants protection and originates from the ICA or the aneurysm neck at an acute angle, stent positioning is through the PcomA only, aligning the proximal portion of the stent with the aneurysm neck. $D$, If the aneurysm neck broadly incorporates both the ICA and the PcomA and the ipsilateral PI is of sufficient caliber to pass a 0.021 microcatheter for stent delivery, stent positioning is retrograde from the PcomA to the terminal ICA.

aneurysm necessitated sacrifice of the PcomA orifice in 3 patients with a hypoplastic-type PcomA. None of the patients had any neurologic complications.

Initial Occlusion Results and Procedural Complications. Successful occlusion after coil embolization was achieved in 24 aneurysms (72.7\%), including total occlusion in 4 and near-total in 20 ; in the other $9(27.3 \%)$, occlusion was subtotal.
Procedure-related complications were few, including 1 instance each of asymptomatic thromboembolism, symptomatic thromboembolic infarction, and stent malpositioning. Of these, only 1 patient experienced minor neurologic sequelae (GOS 4).

Clinical and Radiographic Follow-Up Results. Among the 33 saccular aneurysms, follow-up imaging of 27 aneurysms was performed $>6$ months after coil embolization. This follow-up rate, excluding 6 patients recently retreated ( $<6$ months), constituted $100 \%$. The mean follow-up period for the 27 aneurysms was $15.7 \pm$ 10.7 months, during which imaging showed stable occlusion in 19 aneurysms (70.4\%), minor recanalization in 4 instances (14.8\%), and major recanalization in another 4 (14.8\%).

Conventional angiography was performed as a follow-up in 15 aneurysms $(39.5 \%)>6$ months after coil embolization. Two instances $(13.3 \%)$ of in-stent stenosis were documented, both mild $(<50 \%)$ and asymptomatic. Delayed distal stent migration was observed in 1 patient.

None of the patients experienced delayed infarction during follow-up monitoring.

\section{DISCUSSION}

PcomA aneurysms have unique features in terms of coil embolization. Although classified with the posterior circulation (relative to the risk of rupture) in 1 randomized study (the International Study of Unruptured Intracranial Aneurysms), ${ }^{11}$ Clarke et al ${ }^{12}$ suggested that the rate of rupture for PcomA aneurysms is similar to that of the anterior circulation. These aneurysms may qualify as either bifurcation or sidewall variants, depending on the ratio of PcomA-to-P1 calibers. A study assessing major recurrence of aneurysms treated during the International Subarachnoid Aneurysm Trial indicates that PcomA aneurysms carry a considerably higher risk of major recanalization. ${ }^{13}$ However, the risk of rebleeding is relatively low, with a range of $0.6 \%-2.6 \% .^{2,13,14}$

The protection afforded by stent placement is occasionally limited in wide-neck PcomA aneurysms, particularly when the PcomA originates from the ICA or from the aneurysm neck at an acute angle. In our experience, stents are used less for PcomA aneurysms compared with aneurysms at other intracranial sites or 

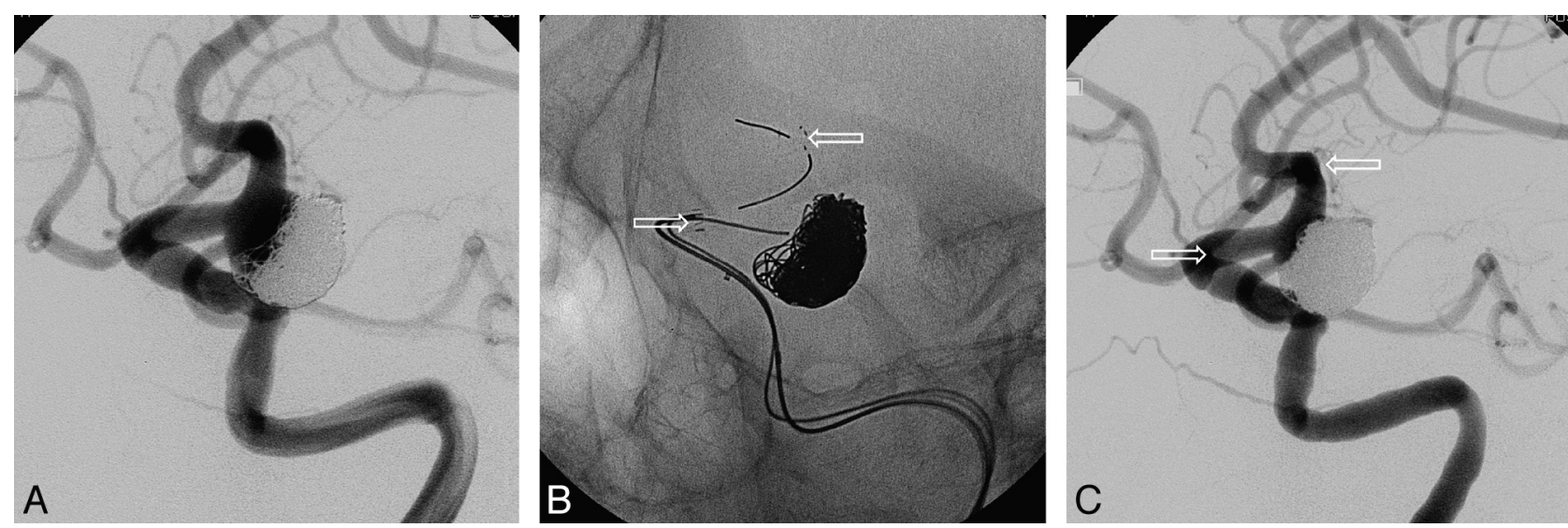

FIG 3. A, Conventional angiography of the recanalized PcomA aneurysm, mostly incorporating the distal ICA. $B$, Coil embolization under stent protection (stent placement through the ICA). C, Completion angiography shows satisfactory occlusion of aneurysm. Arrows indicate both ends of the stent.
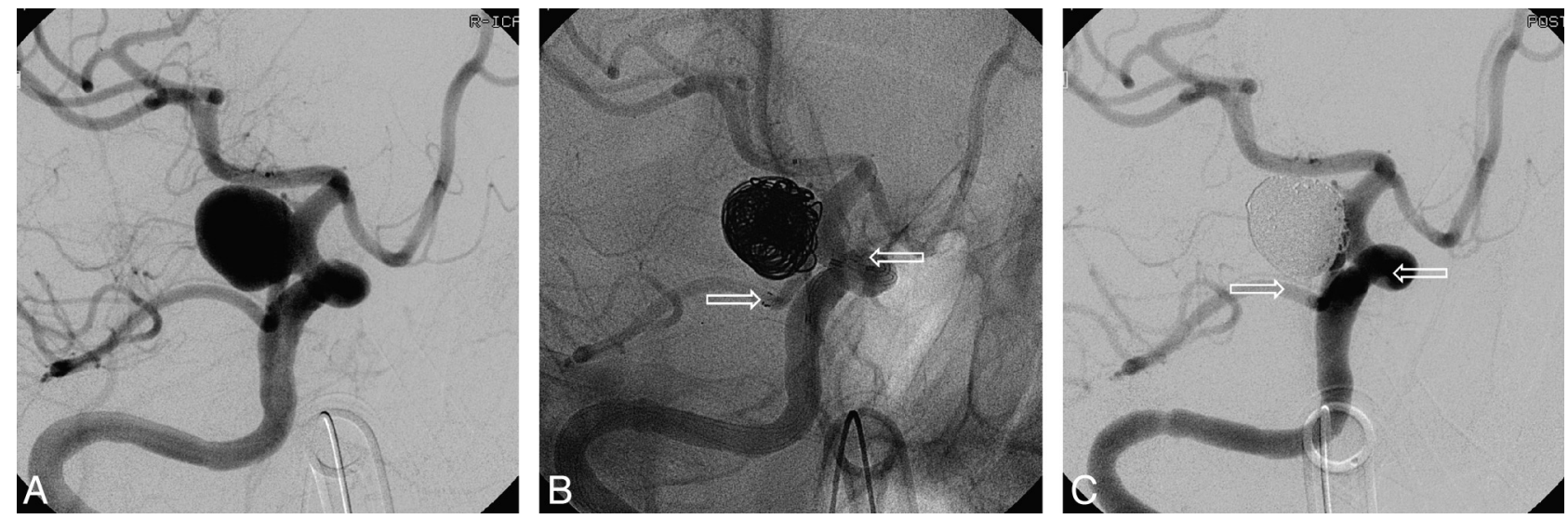

FIG 4. $A$, Conventional angiography of a wide-neck PcomA aneurysm, incorporating the orifice of the PcomA (fetal type). B, An Enterprise stent $(4.5 \times 22 \mathrm{~mm})$ is deployed (distal ICA to the PcomA), and a coil is inserted under stent protection. C, Completion angiography shows occlusion of the aneurysm with a residual neck. Arrows indicate both ends of the stent.

intracranial aneurysms in general. Given that the preservation of both the ICA and PcomA is at stake in this setting, we found that maintenance of patency differed individually, depending on the precise configuration of the aneurysm and the nature of coil embolization achieved. In instances in which the aneurysm neck essentially incorporates the distal ICA or the coil protrudes into the distal ICA, the stent should be placed from the distal ICA to the ICA terminus, covering the distal neck of the aneurysm (Fig 3).

Open-cell stents could be of benefit when protection of the PcomA by a stent inserted through the ICA is required or when the ICA is of a large caliber. If the PcomA is predominantly incorporated into the aneurysm, a stent would serve better by covering the orifice of the PcomA, provided that the caliber of the PcomA is sufficient for stent placement (dominant or fetal type). The angle at which the PcomA originates is also a determinant of stent deployment. Stent placement from the ICA to the PcomA is a viable option if the PcomA originates from the distal ICA at an obtuse angle (Fig 4); whereas stent placement through the PcomA only (aligning the proximal portion of the stent to the aneurysm neck) may be preferable if the PcomA arises from the distal ICA at an acute angle (Fig 5). ${ }^{15}$ Placement from the ICA to the PcomA at an acute-angled origin may induce kink- ing or narrowing ("ovalization") of the stent, but malposition or delayed stent migration is risked if deployment is via the PcomA only. In the event that the aneurysm neck incorporates the ICA and the PcomA in equal measure and the PcomA originates from the ICA at an acute angle, retrograde stent insertion (via the vertebral artery) may be considered, provided that the ipsilateral P1 vessel is of adequate size to pass a microcatheter for stent delivery (Fig 6).

We have devised 4 methods of stent positioning to support coil embolization of PcomA aneurysms, based on aneurysm configuration and specifics of the arterial vasculature. It is our view that stent protection is feasible and efficacious in wide-neck PcomA aneurysms if the stent is positioned in accordance with these variables.

Similar to that in aneurysms in other location, stent protection in wide-neck PcomA aneurysms is not always recommended as a first-line therapeutic strategy because of stent-induced complications such as procedural or delayed thromboembolic infarction and in-stent stenosis. The balloon-remodeling method could have good protection effect, mainly in an ICA-incorporation type. In our series, the balloon-remodeling technique was applied in 35 PcomA aneurysms (35/229, 15.3\%). Flow diverters can also be an alternative option in PcomA aneurysms with wide necks, though they have the possible risk of PcomA occlusion by a compact strut. 

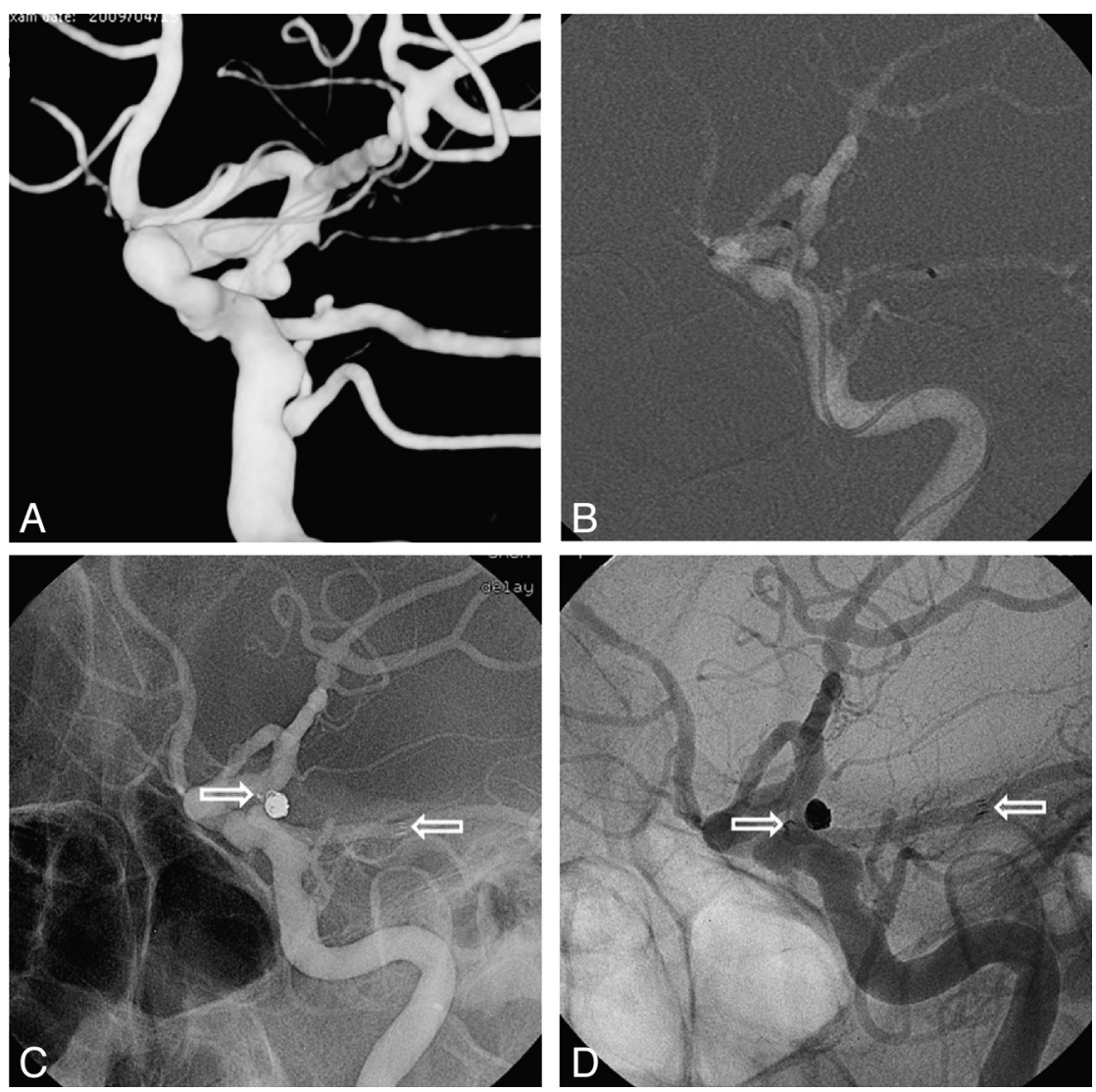

FIG 5. A, 3D image of a wide-neck PcomA aneurysm, mostly incorporating the orifice of the PcomA (PcomA origin at the ICA forms an acute angle). B, Microcatheter for stent delivery is introduced into the PcomA, while a second microcatheter for coil delivery is advanced into the sac of the aneurysm. C, An Enterprise stent $(4.5 \times 22 \mathrm{~mm}$ ) is deployed via the PcomA (aligning the proximal portion of the stent with the neck of the aneurysm) and a coil is inserted successfully under stent protection. $D$, Conventional angiography 12 months later shows an occluded aneurysm and distal stent migration. Arrows indicate both ends of the stent.

Many important vessels branch from the PcomA to supply the optic chiasm, oculomotor nerve, ventral thalamus, mammillary body, tuber cinereum, hypothalamus, and internal capsule. ${ }^{1}$ However, ischemic complications following coil embolization of
PcomA aneurysms are not fully understood, especially when the PcomA is sacrificed. ${ }^{16}$ Although the Allcock test is considered useful for evaluating collateral blood flow, to predict postoperative ischemic complications of PcomA sacrifice, the ramifications of sacrificing the PcomA orifice in patients with PcomA aneurysms are still unknown. Endo et $\mathrm{al}^{16}$ reported 7 cases of tuberothalamic artery territory infarction following coil embolization of 14 ruptured PcomA aneurysms. PcomA sacrifice was regarded as unsafe, even with a preoperative Allcock test confirming retrograde filling of the PcomA by the posterior cerebral artery. Under these circumstances, stent placement in a PcomA aneurysm may preserve PcomA flow, thus avoiding ischemic complications from lack of collateral supply. Coil embolization required PcomA sacrifice in 3 of our patients. All had hypoplastic-type Pco$\mathrm{mAs}$, and retrograde filling of the PcomA with contrast medium was observed by vertebral angiography without carotid compression. None of them had detectable neurologic sequelae.

Because PcomA caliber is a potential issue, an Enterprise stent was used routinely for PcomA stent placement in our patients, on the basis of its ease of navigation and delivery and the microcatheter that is mandatory for deployment. A parent vessel diameter of at least $2.5 \mathrm{~mm}$ is recommended for this device, but we have used it for stent placement in vessels of a 1.7- to $2.1-\mathrm{mm}$ range (mean, $1.9 \pm 0.1 \mathrm{~mm}$ ). Several other sources have reported safely deploying stents in parent arteries $<2.0 \mathrm{~mm}$ in diameter. ${ }^{17-19}$
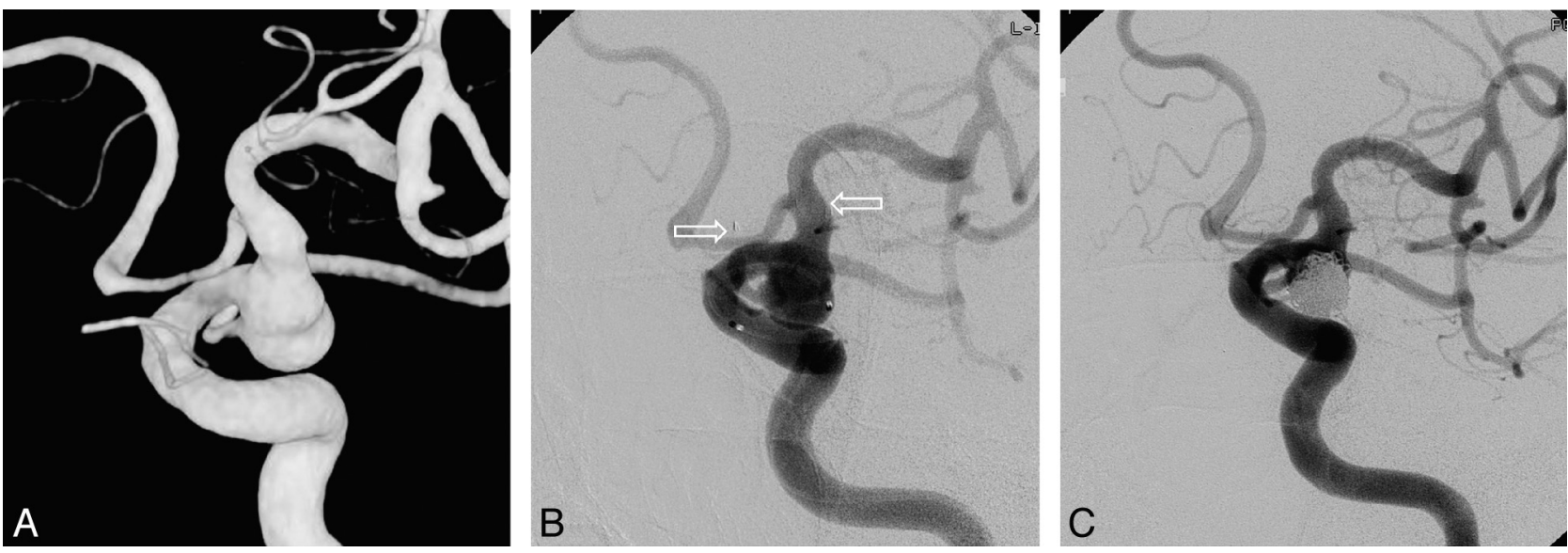

FIG 6. A, 3D image of a wide-neck aneurysm at the PcomA orifice, evenly incorporating the ICA and the orifice of the PcomA (PcomA origin at the neck of the aneurysm forms an acute angle). $B$, Microcatheter for stent delivery is introduced through the ipsilateral $\mathrm{Pl}$ and is navigated retrograde into the left distal ICA via the PcomA; then, the Enterprise stent $(4.5 \times 22 \mathrm{~mm}$ ) is deployed (PcomA to terminal ICA). C, Completion angiography shows occlusion of the aneurysm with a residual neck after coil insertion under stent protection. Arrows indicate both ends of the stent. 
None of our patients developed arterial occlusion or thromboembolism subsequent to stent placement in the PcomA.

\section{CONCLUSIONS}

Despite some limitations, stent-assisted coil embolization of PcomA aneurysms is feasible and efficacious, by using strategies that accommodate the anatomic variations of cerebral vasculature and the array of configurations displayed by these aneurysms.

\section{ACKNOWLEDGMENTS}

We thank Yoon-Kyung Choi for preparation of the illustrations.

Disclosures: Moon Hee Han—RELATED: Consulting Fee or Honorarium: MicroVention, * UNRELATED: Grants/Grants Pending: MicroVention,* Travel/Accommodations/Meeting Expenses Unrelated to Activities Listed: MicroVention. *Money paid to the institution.

\section{REFERENCES}

1. He W, Gandhi CD, Quinn J, et al. True aneurysms of the posterior communicating artery: a systematic review and meta-analysis of individual patient data. World Neurosurg 2011;75:64-72

2. Golshani K, Ferrell A, Zomorodi A, et al. A review of the management of posterior communicating artery aneurysms in the modern era. Surg Neurol Int 2010;1:88

3. Peluso JP, van Rooij WJ, Sluzewski M, et al. A new self-expandable nitinol stent for the treatment of wide-neck aneurysms: initial clinical experience. AJNR Am J Neuroradiol 2008;29:1405-08

4. Weber W, Bendszus M, Kis B, et al. A new self-expanding nitinol stent (Enterprise) for the treatment of wide-necked intracranial aneurysms: initial clinical and angiographic results in 31 aneurysms. Neuroradiology 2007;49:555-61

5. Biondi A, Janardhan V, Katz JM, et al. Neuroform stent-assisted coil embolization of wide-neck intracranial aneurysms: strategies in stent deployment and midterm follow-up. Neurosurgery 2007;61:460-68

6. Piotin M, Blanc R, Spelle L, et al. Stent-assisted coiling of intracranial aneurysms: clinical and angiographic results in 216 consecutive aneurysms. Stroke 2010;41:110-15

7. Higashida RT, Halbach VV, Dowd CF, et al. Initial clinical experience with a new self-expanding nitinol stent for the treatment of intracranial cerebral aneurysms: the Cordis Enterprise stent. AJNR Am J Neuroradiol 2005;26:1751-56

8. Benitez RP, Silva MT, Klem J, et al. Endovascular occlusion of widenecked aneurysms with a new intracranial microstent (Neuroform) and detachable coils. Neurosurgery 2004;54:1359-67

9. Lozen A, Manjila S, Rhiew R, et al. Y-stent-assisted coil embolization for the management of unruptured cerebral aneurysms: report of six cases. Acta Neurochir (Wien) 2009;151:1663-72

10. Kang HS, Kwon BJ, Kim JE, et al. Preinterventional clopidogrel response variability for coil embolization of intracranial aneurysms: clinical implications. AJNR Am J Neuroradiol 2010;31:1206-10

11. Wiebers DO, Whisnant JP, Huston J 3rd, et al, for the International Study of Unruptured Intracranial Aneurysms Investigators. Unruptured intracranial aneurysms: natural history, clinical outcome, and risks of surgical and endovascular treatment. Lancet 2003;362:103-10

12. Clarke G, Mendelow AD, Mitchell P. Predicting the risk of rupture of intracranial aneurysms based on anatomical location. Acta Neurochir (Wien) 2005;147:259-63, discussion 263

13. Campi A, Ramzi N, Molyneux AJ, et al. Retreatment of ruptured cerebral aneurysms in patients randomized by coiling or clipping in the International Subarachnoid Aneurysm Trial (ISAT). Stroke 2007;38:1538-44

14. Raymond J, Guilbert F, Weill A, et al. Long-term angiographic recurrences after selective endovascular treatment of aneurysms with detachable coils. Stroke 2003;34:1398-403

15. Lee SJ, Cho YD, Kang HS, et al. Coil embolization using the selfexpandable closed-cell stent for intracranial saccular aneurysm: a single-center experience of 289 consecutive aneurysms. Clin Radiol 2013;68:256-63

16. Endo H, Sato K, Kondo R, et al. Tuberothalamicartery infarctions following coil embolization of ruptured posterior communicating artery aneurysms with posterior communicating artery sacrifice. AJNR Am J Neuroradiol 2012;33:500-06

17. Roh HG, Chun YI, Choi JW, et al. Retrograde stent placement for coil embolization of a wide-necked posterior inferior cerebellar artery aneurysm. Korean J Radiol 2012;13:510-14

18. Kim MJ, Chung J, Kim SL, et al. Stenting from the vertebral artery to the posterior inferior cerebellar artery. AJNR Am J Neuroradiol 2012;33:348-52

19. Chung J, Kim BS, Lee D, et al. Vertebral artery occlusion with vertebral artery-to-posterior inferior cerebellar artery stenting for preservation of the PICA in treating ruptured vertebral artery dissection. Acta Neurochir (Wien) 2010;152:1489-92 